\title{
Analisis Konsumsi Bahan Bakar Spesifik Pada Pembangkit Listrik Tenaga Uap (PLTU) Jeneponto
}

\author{
Jamal $^{1 *}$, Chandra Bhuana ${ }^{2}$, dan Fajri Alihar ${ }^{3}$ \\ 1,2,3 Jurusan Teknik Mesin, Politeknik Negeri Ujung Pandang, Makassar 90245, Indonesia \\ *jamal_mesin@poliupg.ac.id
}

\begin{abstract}
This study aims to determine the relationship of the heating value of fuel to SFC in Jeneponto power plant unit I, and to find out the characteristics of the SFC relationship with different generator load variations in the unit I Jeneponto power plant, and to determine the characteristics of the relationship between SFC and system efficiency in unit I Jeneponto power plant. The study was conducted by processing secondary data obtained from the Jeneponto power plant, also conducted field observations and interviews with several employees and operators of the Jeneponto power plant. The results obtained are the highest average calorie value having a low SFC value and vice versa. This proves that the higher the calorific value contained in coal, the lower specific fuel consumption (SFC) and vice versa. At a loading of 50-60\% of the installed capacity of $1 \times 125 \mathrm{MW}$ gives a relatively high SFC value, while loading above $80 \%$ of the installed capacity of $1 \times 125 \mathrm{MW}$ gives a relatively low SFC value, this means the plant can work optimally if operated at a load above $80 \%$. A low SFC value has a high efficiency and a high SFC value has a low efficiency, this condition shows that the higher the SFC value of the plant, the lower the efficiency of the system and vice versa.
\end{abstract}

Keywords: power plant; SFC value; Heat value

\begin{abstract}
Abstrak: Penelitian ini bertujuan untuk mengetahui hubungan nilai kalor bahan bakar terhadap SFC pada unit I PLTU Jeneponto, dan untuk mengetahui karakteristik hubungan SFC dengan variasi beban generator yang berbeda pada unit I PLTU Jeneponto, serta untuk mengetahui karakteristik hubungan SFC dengan efesiensi sistem pada unit I PLTU Jeneponto. Penelitian dilakukan dengan mengolah data sekunder yang didapatkan dari PLTU Jeneponto, juga dilakukan observasi lapangan dan wawancara dengan beberapa pegawai dan operator PLTU Jeneponto. Hasil yang diperoleh adalah rata-rata nilai kalori yang tertinggi memiliki nilai SFC yang rendah dan sebaliknya. Hal ini membuktikan bahwa semakin tinggi nilai kalori yang terdapat pada batubara maka konsumsi bahan bakar spesifiknya (SFC) semakin rendah begitupun sebaliknya. Pada pembebanan 50-60\% dari kapasitas terpasang $1 \times 125 \mathrm{MW}$ memberikan nilai SFC yang relatif tinggi, sedangkan pada pembebanan diatas $80 \%$ dari kapasitas terpasang $1 \times 125 \mathrm{MW}$ memberikan nilai SFC yang relatif rendah, ini artinya pembangkit dapat bekerja optimal jika dioperasikan pada pembebanan diatas $80 \%$. Nilai SFC yang rendah memiliki efesiensi yang tinggi dan nilai SFC yang tinggi memiliki efesiensi yang rendah, kondisi ini memperlihatkan bahwa semakin tinggi nilai SFC pembangkit tersebut maka semakin rendah efesiensi sistemnya begitu pun sebaliknya.
\end{abstract}

Kata kunci : PLTU; nilai SFC; nilai Kalor

\section{PENDAhuluan}

Secara umum, pengertian pembangkit listrik tenaga uap (PLTU) adalah pembangkit listrik yang mengandalkan energi kinetik dari uap untuk menghasilkan energi listrik. Uap merupakan sumber energi sekunder di dalam sistem PLTU, sedangkan bahan bakar yang digunakan untuk memproduksi uap tersebut merupakan sumber energi primer.

Untuk menghasilkan energi listrik pada PLTU Batubara ini, awalnya batu bara yang ditampung dalam bak penampungan dibawa ke dalam mesin pencacah batubara melalui conveyor belt untuk dipecah menjadi ukuran yang lebih kecil/halus, hal ini berguna agar batubara lebih mudah terbakar pada saat di dalam boiler. Batubara yang telah halus tadi dibawa ke dalam boiler untuk digunakan sebagai bahan bakar pada proses pembakaran pada boiler ini terjadi proses pemanasan air yang sebelumnya telah dimurnikan agar tidak mudah menimbulkan korosi (untuk air laut), air tersebut melalui pipa-pipa boiler dan dipanaskan sehingga akan berubah menjadi uap panas yang bertekanan tinggi. Tetapi karena kadar air pada uap masih terlalu tinggi, maka kadar air harus dihilangkan 
terlebih dahulu melalui superheater sehingga akan berubah menjadi uap kering. Kemudian uap kering ini dialirkan menuju ke turbin untuk mendorong sudu-sudu turbin sehingga poros turbin akan berputar. Setelah digunakan untuk memutar turbin, maka uap kering akan turun kembali ke lantai dasar. Uap tersebut akan didinginkan di dalam kondensor, dengan menggunakan air pendingin (biasanya air laut atau air sungai) yang dialirkan melalui pipa-pipa di dalam kondensor akan mendinginkan uap sehingga kembali menjadi air, kemudian air tersebut dapat disirkulasikan kembali ke boiler untuk dipanaskan menjadi uap kembali dan digunakan untuk memutar turbin, karena poros turbin ini sudah dikopel dengan generator sehingga ketika turbin berputar maka generator juga akan ikut berputar. Karena generator ikut berputar maka akan menghasilkan energi listrik yang akan dikirimkan ke trafo untuk dirubah tegangannya dan kemudian disalurkan melalui saluran transmisi PLN.

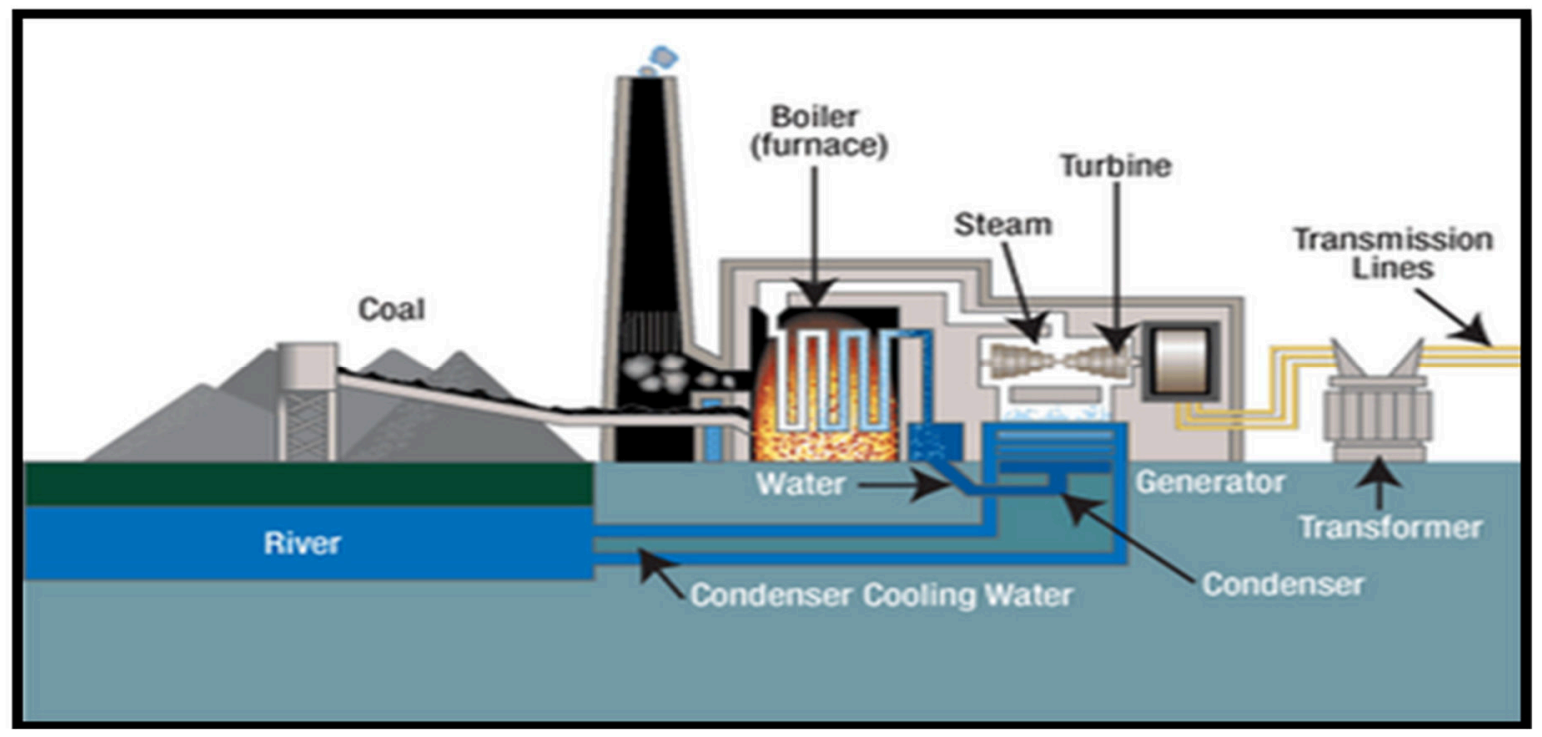

Gambar 1. Diagram Alir Pembangkit Listrik Tenaga Uap

Sumber : https://www.slideshare.net/rafirmansyah5/pltu-batubara-s

PLTU Jeneponto unit I PT. Bosowa Energi yang berkapasitas 1x125 MW menggunakan bahan bakar batubara sebagai proses pembakaraan untuk menguapkan air. Bahan bakar batubara dalam penggunaannya pada PLTU memiliki peranan penting karena setiap pertambahaan beban akan mendorong pertambahaan kuantitas bahan bakar per satuan waktu yang dapat mengakibatkan pembangkit tidak efisien. Total konsumsi bahan bakar juga mempengaruhi koefisien efisiensi PLTU. Hal tersebut berpengaruh terhadap daya listrik yang dibangkitkan dalam sebuah industri pembangkitan listrik. Jika pemakaian bahan bakar batubara tidak sebanding dengan daya listrik yang dihasilkan dapat menimbulkan kerugian baik bagi PLTU itu sendiri maupun pihak yang terkait. Kerugian tersebut akan berdampak pada besarnya selisih biaya bahan bakar per $\mathrm{kWh}$ daya pembangkitan terhadap harga jual (tarif listrik) ke konsumen. Oleh karena itu, perlunya menganalisa pemakaian bahan bakar sehingga biaya produksi energi listrik lebih ekonomis. Dengan hadirnya specific fuel consumption (SFC) sebagai salah satu cara untuk mengetahui seberapa efisien sebuah pembangkit listrik dan untuk memprediksi nilai kalor bahan bakar yang digunakan untuk pembakaran.

Salah satu parameter yang digunakan pada suatu sistem pembangkit tenaga berbahan bakar bakar batubara adalah SFC atau konsumsi batubara spesifik. SFC adalah jumlah batubara yang konsumsi oleh suatu unit PLTU untuk menghasilkan daya satu kilowatt selama satu jam $(\mathrm{kg} / \mathrm{kWh})$. Nilai SFC dipengaruhi dengan kualitas bahan bakar batubara dan kondisi beban yang harus dilayani PLTU. 


\section{Jamal, Chandra Bhuana, Fajri Alihar. Analisis Konsumsi Bahan Bakar Spesifik Pada Pembangkit Listrik}

Tenaga Uap (PLTU) Jeneponto

Semakin rendah nilai SFC maka semakin efisien pemakaian bahan bakarnya. Selain itu dengan diketahui nilai SFC, nilai biaya produksi listriknya dapat ditentukan.

Penelitian tentang analisis konsumsi bahan bakar pada pembangkit listrik tenaga uap telah banyak dilakukan diantaranya yaitu studi kasus di PT. Indonesia Power UBP. PLTGU Priok dengan menggunakan metode multi criteria decition making [1], studi kasus yang lain Di PT. Indonesia Power Semarang yang dilakukan pada PLTU [2], studi kasus juga dilakukan pada PT. PLN Pembangkit Tanjung Jati yang juga dilakukan di PLTU [3], juga telah dilakukan analisis konsumsi bahan bakar pada PLTU dengan menggunakan metode least square [4].

Penelitian lain yang juga dilakukan adalah analisis konsumsi bahan bakar yang berhubungan dengan kualitas bahan bakarnya, saat ini di Indonesia yang umum digunakan adalah bahan bakar batubara, sehingga pengaruh nilai kalor batubara juga berdampak terhadap konsumsi bahan bakar [56], kualitas bahan bakar batubara juga berdampak pada biaya produksi dan biaya pembangkitan [6-7].

\section{METODE PENELITIAN}

Penelitian dilakukan dengan menggunakan metode yang mengolah data sekunder yang didapatkan dari PLTU Jeneponto. Untuk menguatkan data maka dilakukan observasi lapangan, yakni pengamatan langsung di PLTU Jeneponto, untuk mengetahui dan menguatkan data yang diperoleh serta agar dapat memahami data yang diberikan oleh PLTU Jeneponto. Langkah lain yang dilakukan agar mendapatkan informasi yang lengkap adalah dengan melakukan wawancara, yakni berkomunikasi langsung dan tanya jawab dengan beberapa pegawai dan operator PLTU Jeneponto.

\section{HASIL DAN PEMBAHASAN}

Berikut adalah sekunder yang diperoleh dari PLTU jeneponto. Data yang diperoleh yang akan dikelolah adalah data pada bulan April 2018.

Tabel 1. Data Operasi Pembangkit Unit I per-jam

\begin{tabular}{|c|c|c|c|c|c|c|c|}
\hline $\begin{array}{c}\text { Tanggal } \\
\text { Operasi } \\
\text { (Thn 2018) }\end{array}$ & $\begin{array}{c}\text { Waktu } \\
\text { Operasi } \\
(\mathrm{Jam})\end{array}$ & $\begin{array}{c}\text { Beban } \\
\text { Generator } \\
(\mathrm{MW})\end{array}$ & $\begin{array}{c}\text { Laju Bhn } \\
\text { Bakar } \\
\text { (ton/jam) }\end{array}$ & $\begin{array}{c}\text { Tanggal } \\
\text { Operasi } \\
\text { (Thn 2018) }\end{array}$ & $\begin{array}{c}\text { Waktu } \\
\text { Operasi } \\
(\text { Jam })\end{array}$ & $\begin{array}{c}\text { Beban } \\
\text { Generator } \\
(\mathrm{MW})\end{array}$ & $\begin{array}{c}\text { Laju Bhn } \\
\text { Bakar } \\
\text { (ton/jam })\end{array}$ \\
\hline April 1 & $0: 00$ & 72.42 & 46.68 & April 1 & $12: 00$ & 73.86 & 46.99 \\
\hline April 1 & $1: 00$ & 73.62 & 46.36 & April 1 & $13: 00$ & 73.99 & 46.83 \\
\hline April 1 & $2: 00$ & 73.32 & 46.45 & April 1 & $14: 00$ & 74.97 & 46.92 \\
\hline April 1 & $3: 00$ & 72.31 & 46.48 & April 1 & $15: 00$ & 74.56 & 46.32 \\
\hline April 1 & $4: 00$ & 71.52 & 46.47 & April 1 & $16: 00$ & 73.83 & 46.59 \\
\hline April 1 & $5: 00$ & 70.72 & 46.38 & April 1 & $17: 00$ & 72.98 & 46.63 \\
\hline April 1 & $6: 00$ & 70.53 & 46.48 & April 1 & $18: 00$ & 91.52 & 59.07 \\
\hline April 1 & $7: 00$ & 72.13 & 46.48 & April 1 & $19: 00$ & 96.52 & 50.81 \\
\hline April 1 & $8: 00$ & 72.13 & 46.43 & April 1 & $20: 00$ & 99.14 & 50.96 \\
\hline April 1 & $9: 00$ & 71.34 & 46.41 & April 1 & $21: 00$ & 102.22 & 50.42 \\
\hline April 1 & $10: 00$ & 71.46 & 46.44 & April 1 & $22: 00$ & 93.68 & 53.14 \\
\hline April 1 & $11: 00$ & 72.76 & 46.97 & April 1 & $23: 00$ & 74.19 & 47.37 \\
\hline
\end{tabular}


Tabel 2. Data Operasi Pembangkit Unit I Per-hari

\begin{tabular}{|c|c|c|c|c|c|c|c|}
\hline $\begin{array}{c}\text { Tanggal } \\
\text { Operasi } \\
\text { (Thn 2018) }\end{array}$ & $\begin{array}{c}\text { Beban } \\
\text { Generator } \\
(\mathrm{MW})\end{array}$ & $\begin{array}{c}\text { Laju Bhn } \\
\text { Bakar } \\
\text { (ton/jam })\end{array}$ & $\begin{array}{c}\text { Nilai Kalori } \\
\text { Bhn bakar } \\
(\mathrm{kcal} / \mathrm{kg})\end{array}$ & $\begin{array}{c}\text { Tanggal } \\
\text { Operasi } \\
(\text { Thn 2018) }\end{array}$ & $\begin{array}{c}\text { Beban } \\
\text { Generator } \\
(\mathrm{MW})\end{array}$ & $\begin{array}{c}\text { Laju Bhn } \\
\text { Bakar } \\
\text { (ton/jam) }\end{array}$ & $\begin{array}{c}\text { Nilai Kalori } \\
\text { Bhn bakar } \\
(\mathrm{kcal} / \mathrm{kg})\end{array}$ \\
\hline 1 April & 77.74 & 47.92 & 4044.4 & 16 April & 76.89 & 46.62 & 4502.7 \\
\hline 2 April & 81.91 & 50.73 & 4113.8 & 17 April & 77.85 & 48.08 & 4517.2 \\
\hline 3 April & 82.14 & 51.15 & 4416.2 & 18 April & 78.53 & 47.63 & 4443.5 \\
\hline 4 April & 77.35 & 52.52 & 4350.2 & 19 April & 82.76 & 51.98 & 3830.7 \\
\hline 5 April & 83.29 & 53.79 & 4417.7 & 20 April & 70.43 & 45.55 & 3078.6 \\
\hline 6 April & 76.80 & 50.33 & 4191.4 & 21 April & 71.38 & 44.50 & 3083.6 \\
\hline 7 April & 75.79 & 49.94 & 4278.2 & 22 April & 69.52 & 43.96 & 4187.3 \\
\hline 8 April & 76.36 & 49.04 & 3385.8 & 23 April & 74.70 & 45.04 & 3181.4 \\
\hline 9 April & 81.55 & 50.85 & 3892.3 & 24 April & 69.15 & 40.98 & 4596.7 \\
\hline 10 April & 90.42 & 59.62 & 3677.2 & 25 April & 84.05 & 51.80 & 4411.0 \\
\hline 11 April & 92.92 & 59.77 & 3633.1 & 26 April & 74.48 & 46.37 & 4466.0 \\
\hline 12 April & 94.64 & 60.24 & 3441.4 & 27 April & 69.95 & 45.03 & 4355.0 \\
\hline 13 April & 91.53 & 62.31 & 4588.1 & 28 April & 68.95 & 44.53 & 3626.3 \\
\hline 14 April & 76.35 & 49.30 & 3003.4 & 29 April & 69.04 & 43.13 & 4226.7 \\
\hline 15 April & 77.19 & 48.52 & 3070.3 & 30 April & 81.07 & 46.30 & 3643.9 \\
\hline
\end{tabular}

A. Perhitungan Data

1. Spesifik Fuel Consumption (SFC) dan Efesiensi Sistem (1) Data Per-Jam.

- Mengitung nilai laju aliran batubara $\left(\dot{\mathrm{m}}_{\mathrm{bb}}\right)$ data ke-1 tabel 1 data per-jam pada halaman 4 : Penyelesaian :

$\dot{\mathrm{m}}_{\mathrm{bb}}=46,68 \frac{\text { ton }}{\mathrm{jam}}=46,68 \frac{\mathrm{ton}}{\mathrm{jam}} \times \frac{1000 \mathrm{~kg}}{1 \text { ton }} \times \frac{1 \mathrm{jam}}{3600 \mathrm{~s}}=12,97 \frac{\mathrm{kg}}{\mathrm{s}}$

- Mengkonversi satuan nilai kalor data ke-1 pada tabel 1 :

Penyelesaian :

Nilai Kalor $=4044,4 \frac{\mathrm{kcal}}{\mathrm{kg}}=4044,4 \frac{\mathrm{kcal}}{\mathrm{kg}} \times 4,184 \frac{\mathrm{kj}}{\mathrm{kcal}}=16921,76 \frac{\mathrm{kJ}}{\mathrm{kg}}$

- Menghitung nilai $P_{\text {out }}$ data ke-1 pada tabel 1 :

Penyelesaian :

Nilai $\mathrm{P}_{\text {out }}$ didapatkan dari pengkonversian nilai beban generator dari $\mathrm{MW}$ ke $\mathrm{kW}$.

Beban generator $=72,74 \mathrm{MW} \times 1000 \frac{\mathrm{kW}}{\mathrm{MW}}=72420 \mathrm{~kW}$.

- Menghitung nilai $P_{\text {in }}$ data ke-1 pada tabel 1 :

Penyelesaian :

Nilai $\mathrm{P}_{\mathrm{in}}=\dot{\mathrm{m}}_{\mathrm{bb}} \times$ Nilai kalor $=12,97 \frac{\mathrm{kg}}{\mathrm{s}} \times 16921,76 \frac{\mathrm{kJ}}{\mathrm{kg}}=219475,3 \mathrm{~kW}$

- Menghitung nilai SFC data ke-1 pada tabel 1 :

Penyelesaian :

$\mathrm{SFC}=\frac{\dot{\mathrm{m}}_{\mathrm{bb}} \times 3600}{\text { Power gross } \times 1000}=\frac{12,96 \frac{\mathrm{kg}}{\mathrm{s}} \times 3600 \mathrm{~s}}{72,42 \mathrm{MW} \times 1000 \mathrm{~kW} \times 1 \mathrm{Jam}}=0,64 \frac{\mathrm{kg}}{\mathrm{kWh}}$

- Menghitung efesiensi (1) sistem PLTU data ke-1 pada tabel 3.4.1 :

Penyelesaian :

Efesiensi $(\Pi)=\frac{\mathrm{P}_{\text {out }}}{\mathrm{P}_{\text {in }}} \times 100 \%=\frac{72420 \mathrm{~kW}}{219475,3 \mathrm{~kW}} \times 100 \%=33,00 \%$

2. Spesifik Fuel Consumption (SFC) dan Efesiensi Sistem (1) Data Per-Hari.

- Mengitung nilai laju aliran batubara $\left(\dot{\mathrm{m}}_{\mathrm{bb}}\right)$ data ke-1 pada tabel 2 data per-hari pada halaman 5 : 
24 Jamal, Chandra Bhuana, Fajri Alihar. Analisis Konsumsi Bahan Bakar Spesifik Pada Pembangkit Listrik Tenaga Uap (PLTU) Jeneponto

Penyelesaian :

$\dot{\mathrm{m}}_{\mathrm{bb}}=47,92 \frac{\text { ton }}{\mathrm{jam}}=47,92 \frac{\text { ton }}{\mathrm{jam}} \times \frac{1000 \mathrm{~kg}}{1 \text { ton }} \times \frac{1 \mathrm{jam}}{3600 \mathrm{~s}}=13,31 \frac{\mathrm{kg}}{\mathrm{s}}$

- Mengkonversi satuan nilai kalor data ke-1 pada tabel 2 :

Penyelesaian :

Nilai Kalor $=4044,4 \frac{\mathrm{kcal}}{\mathrm{kg}}=4044,4 \frac{\mathrm{kcal}}{\mathrm{kg}} \times 4,184 \frac{\mathrm{kj}}{\mathrm{kcal}}=16921,7696 \frac{\mathrm{kJ}}{\mathrm{kg}}$

- Menghitung nilai $P_{\text {out }}$ data ke-1 pada tabel 2 :

Penyelesaian :

Nilai $\mathrm{P}_{\text {out }}$ didapatkan dari pengkonversian nilai beban generator dari $\mathrm{MW}$ ke $\mathrm{kW}$.

Beban generator $=77,74 \mathrm{MW} \times 1000 \frac{\mathrm{kW}}{\mathrm{MW}}=77740 \mathrm{~kW}$.

- Menghitung nilai $P_{\text {in }}$ data ke-1 pada tabel 2 :

Penyelesaian :

Nilai $\mathrm{P}_{\mathrm{in}}=\dot{\mathrm{m}}_{\mathrm{bb}} \times$ Nilai kalor $=13,31 \frac{\mathrm{kg}}{\mathrm{s}} \times 16921,76 \frac{\mathrm{kJ}}{\mathrm{kg}}=225228,6 \mathrm{~kW}$.

- Menghitung nilai SFC data ke-1 pada tabel 2 :

Penyelesaian :

$\mathrm{SFC}=\frac{\dot{\mathrm{m}}_{\mathrm{bb}} \times 3600}{\text { Power gross } \times 1000}=\frac{13,31 \frac{\mathrm{kg}}{\mathrm{s}} \times 3600 \mathrm{~s}}{77,74 \mathrm{MW} \times 1000 \mathrm{~kW} \times 1 \mathrm{Jam}}=0,61 \frac{\mathrm{kg}}{\mathrm{kWh}}$

- Menghitung efesiensi (1) sistem PLTU data ke-1 pada tabel 2 :

Penyelesaian :

Efesiensi $(\Pi)=\frac{\mathrm{P}_{\text {out }}}{\mathrm{P}_{\text {in }}} \times 100 \%=\frac{77740 \mathrm{~kW}}{225228,6 \mathrm{~kW}} \times 100 \%=34,52 \%$

B. Pembahasan Grafik

Berdasarkan hasil perhitungan SFC dan efesiensi sistem (I) per-jam dan per-hari unit I PLTU Jeneponto, maka dapat digambarkan beberapa grafik sebagai berikut

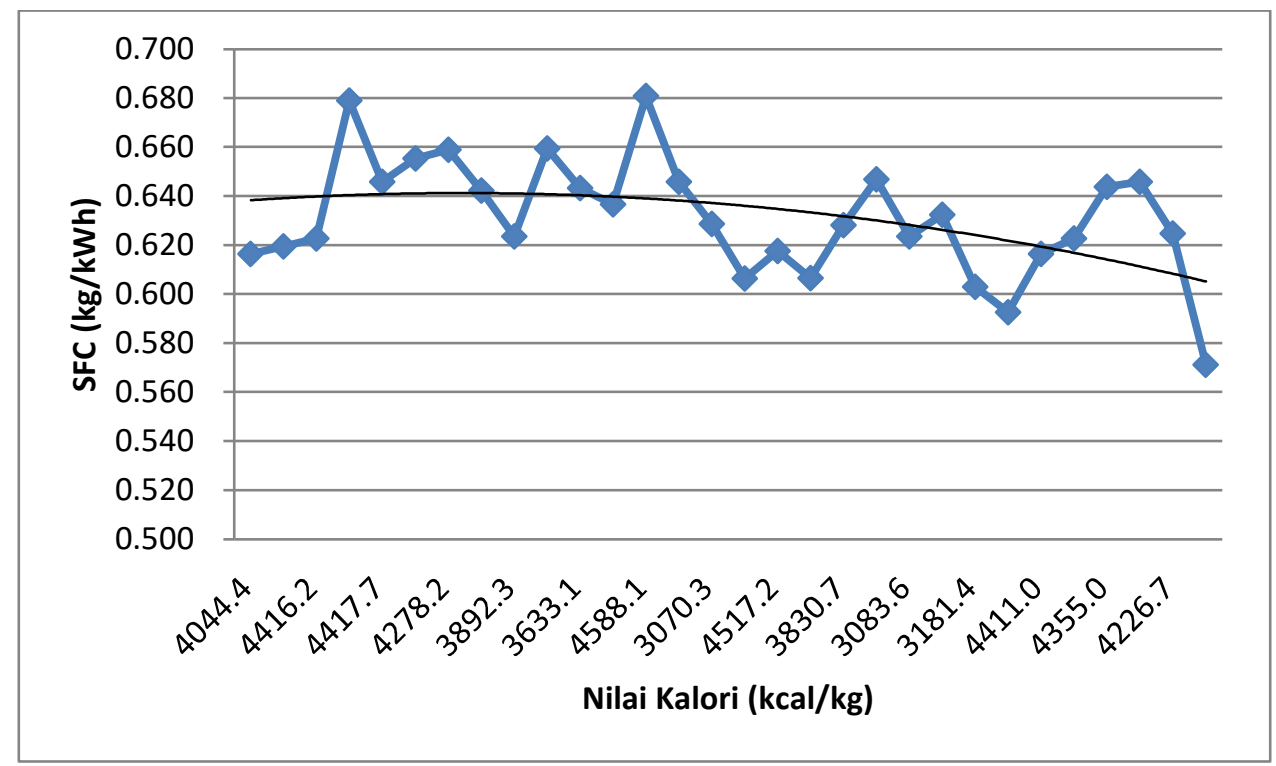

Gambar 2. Hubungan Pengaruh SFC Terhadap Nilai Kalori Bahan Bakar Data Per-hari. 
Gambar 2, memperlihatkan hubungan pengaruh SFC terhadap nilai kalori data per-hari, dimana nilai SFC rendah yakni sekitar $0,593 \mathrm{~kg} / \mathrm{kWh}$ memiliki nilai kalori yang tinggi sebesar $4596 \mathrm{kcal} / \mathrm{kg}$ dan sebaliknya nilai SFC tinggi $0,646 \mathrm{~kg} / \mathrm{kWh}$ memiliki nilai kalor yang rendah sebesar 3003,4 $\mathrm{kcal} / \mathrm{kg}$. Hal ini sesuai dengan teori yang ada yakni semakin tinggi nilai kalori yang terdapat pada batubara maka SFCnya rendah, yang artinya semakin tinggi nilai kalori yang dipakai semakin sedikit bahan bakar yang dipakai untuk menghasilkan $1 \mathrm{kWh}$ listrik. Akan tetapi ada ketidaksesuain teori yang terjadi pada saat nilai kalori batubaranya yang relatif besar dan nilai SFCnya juga besar seperti saat nilai kalorinya sebesar $4355 \mathrm{kcal} / \mathrm{kg}$ dan SFCnya $0,644 \mathrm{~kg} / \mathrm{kWh}$, hal ini kemungkinan disebabkan karena beberapa faktor antara lain karena adanya kerugian kehilangan panas pada sistem PLTU sehingga dapat mempengaruhi panas boiler yang berdampak pada nilai SFCnya.

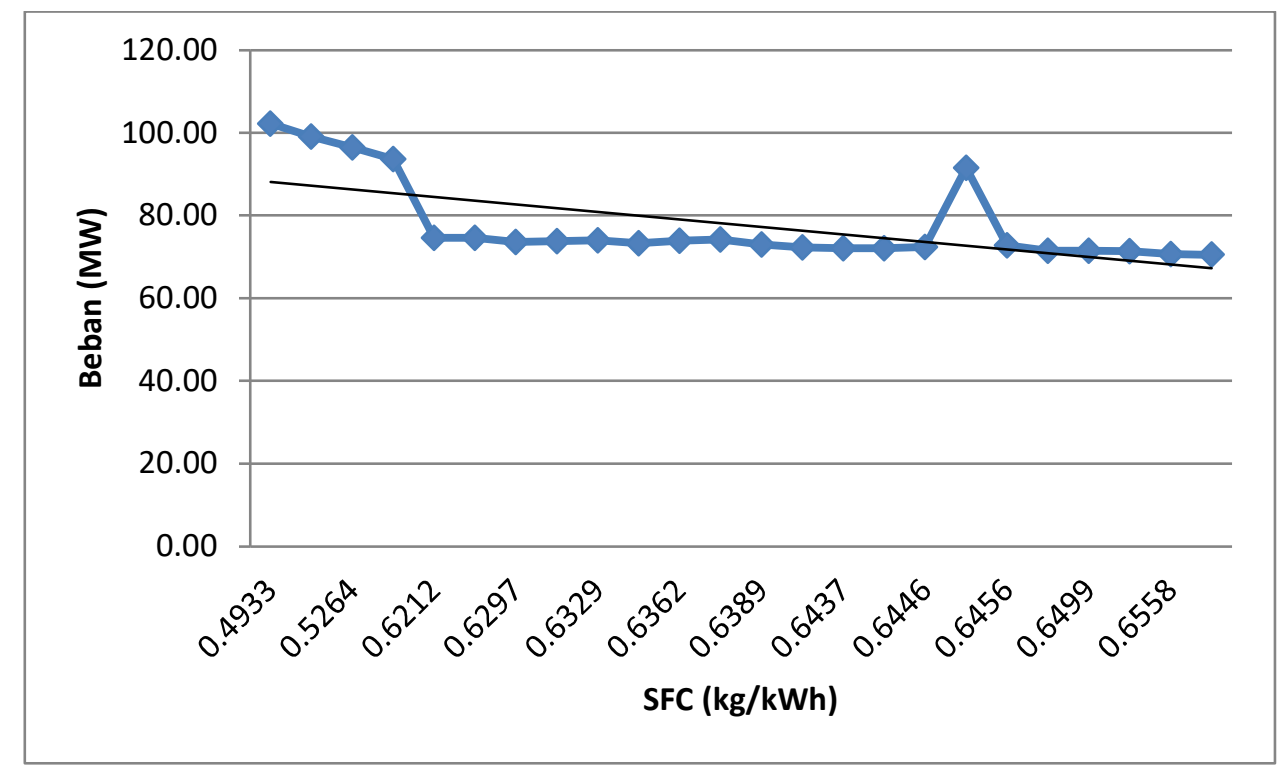

Gambar 3. Hubungan Pengaruh Beban Generator Terhadap SFC Data Per-Jam.

Gambar 3, memperlihatkan hubungan pengaruh beban generator terhadap SFC, dimana pada pembebanan sekitar 102,22 MW (81,6 \%) sampai 91,52 MW (73,2\%) dari kapasitas terpasang pembangkit unit I PLTU Jeneponto memiliki nilai SFC yang rendah sekitar 0,49 $\mathrm{kg} / \mathrm{kWh}$ sampai 0,56 $\mathrm{kg} / \mathrm{kWh}$, sedangkan pada pembebanan rata-rata $60 \%$ atau sekitar $73 \mathrm{MW}$ memiliki nilai SFC yang rata-rata tinggi sekitar $0,63 \mathrm{~kg} / \mathrm{kWh}-0,65 \mathrm{~kg} / \mathrm{kWh}$, kondisi ini memperlihatkan bahwa pembangkit listrik tenaga uap yang ada di Jeneponto akan bekerja optimal jika dioperasikan pada pembebanan diatas $80 \%$ dari kapasitas terpasang pembangkit, hal ini juga akan memberikan penghematan penggunaan bahan bakar maksimal sebesar $20 \%$.

Gambar 4, memperlihatkan hubungan pengaruh beban generator terhadap SFC, grafik ini adalah grafik fluktuatif dimana selama satu bulan beban 94,64 MW (76\%) dari kapasitas terpasang $1 \times 125 \mathrm{MW}$ merupakan beban generator tertinggi yang memiliki nilai SFC $0,637 \mathrm{~kg} / \mathrm{kWh}$, sedangkan pada beban $71,38 \mathrm{MW}(57 \%)$ dari kapasitas terpasang $1 \times 125 \mathrm{MW}$ merupakan beban generator terendah yang memiliki nilai SFC $0,623 \mathrm{~kg} / \mathrm{kWh}$, kondisi ini memperlihatkan bahwa pembangkit listrik tenaga uap yang ada di Jeneponto akan bekerja optimal jika dioperasikan pada pembebanan yang relatif lebih tinggi. 
26 Jamal, Chandra Bhuana, Fajri Alihar. Analisis Konsumsi Bahan Bakar Spesifik Pada Pembangkit Listrik Tenaga Uap (PLTU) Jeneponto

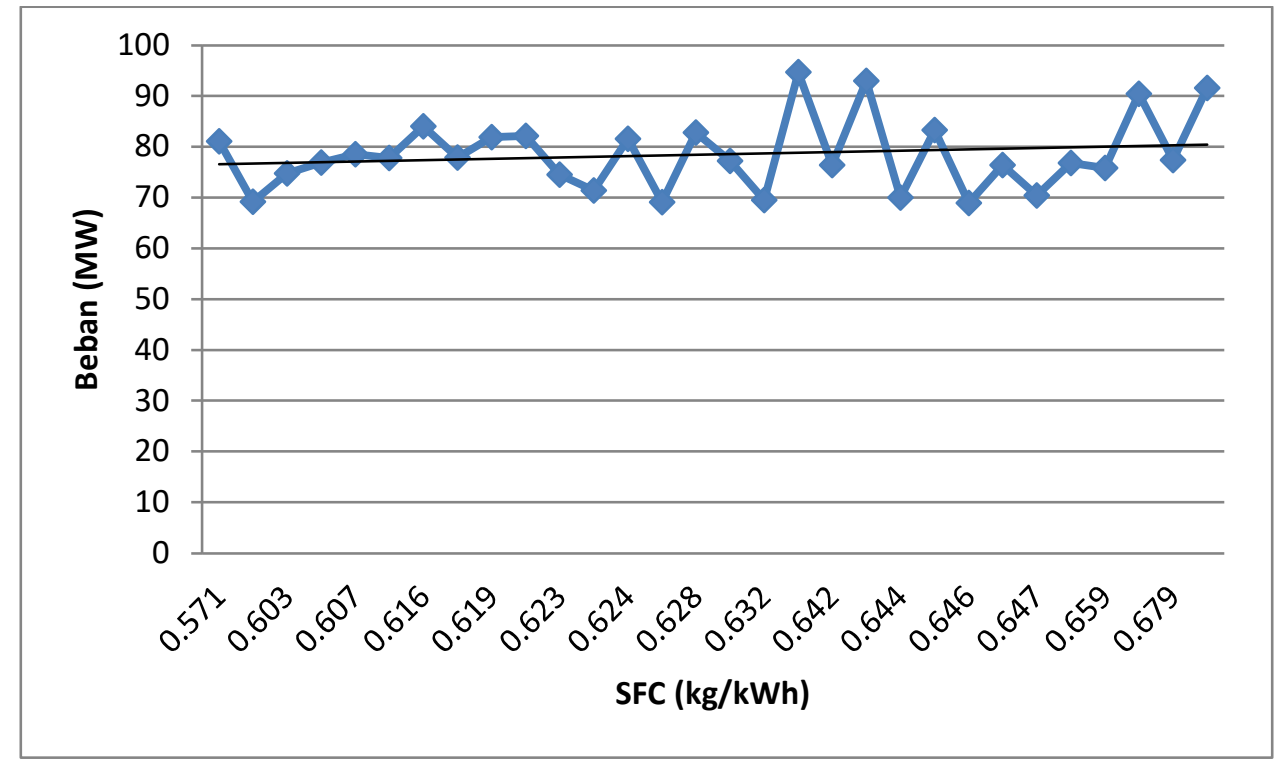

Gambar 4. Hubungan Pengaruh Beban Generator Terhadap SFC Data Per-Hari.

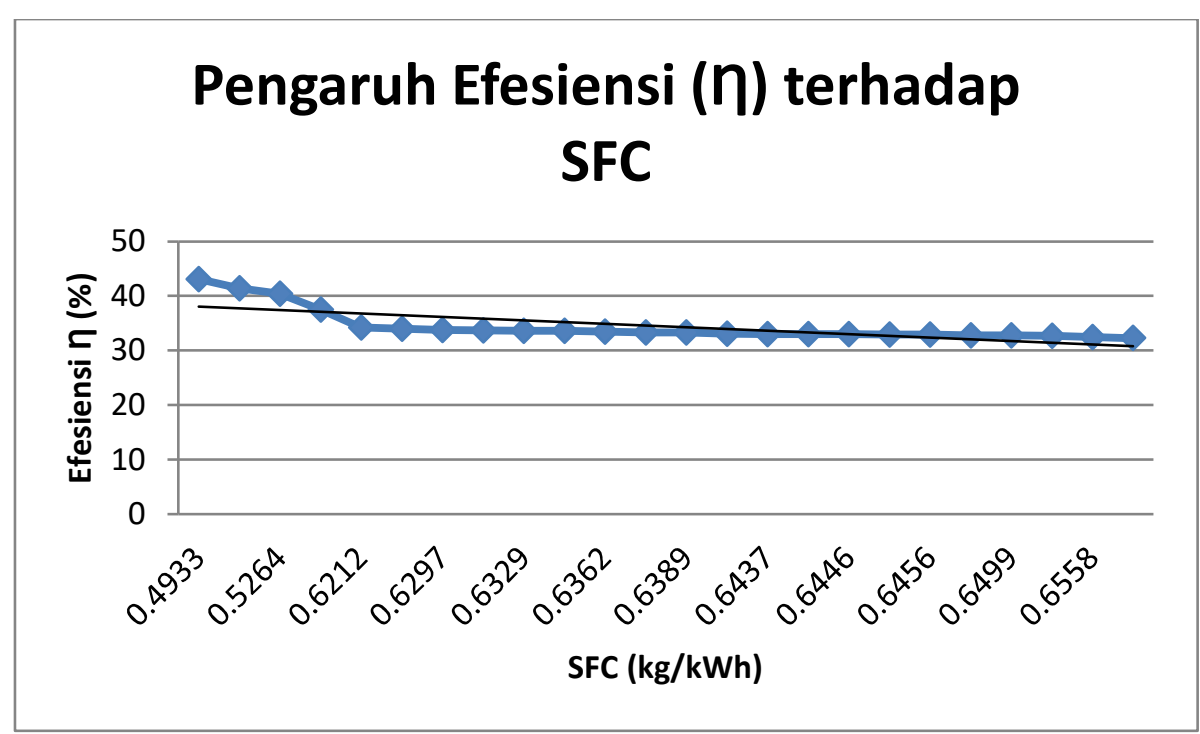

Gambar 5. Hubungan Pengaruh Efesiensi (1) Terhadap SFC Data Per-Jam.

Gambar 5, memperlihatkan hubungan pengaruh efesiensi (M) terhadap SFC, dimana nilai SFC yang rendah memiliki efesiensi yang tinggi seperti pada saat nilai SFCnya sekitar $0,49 \mathrm{~kg} / \mathrm{kWh}$ memiliki efesiensi $43 \%$, sebaliknya apabila nilai SFCnya tinggi maka efesiensinya rendah seperti pada saat nilai SFCnya sekitar $0,65 \mathrm{~kg} / \mathrm{kWh}$ memiliki efesiensi $32 \%$, kondisi ini memperlihatkan bahwa semakin tinggi nilai SFC pembangkit tersebut maka semakin rendah efesiensi sistemnya begitu pun sebaliknya.

Gambar 6, memperlihatkan hubungan pengaruh efesiensi (П) terhadap SFC, berbeda dengan data perjam, grafik pengaruh efesiensi teradap SFC pada data perhari cenderung fluktuatif, ini diakibatkan pengaruh nilai kalor yang berbeda, tapi sama halnya dengan data perjam dimana apabila nilai SFC rendah maka efesiensi sistemnya tinggi begitupun sebaliknya, hal ini terbukti pada saat nilai SFC $0,57 \mathrm{~kg} / \mathrm{kWh}$ dengan kata lain nilai SFCnya rendah memiliki efesiensi sistem yang tinggi sebesar 
$42 \%$, sedangkan pada saat nilai SFC $0,67 \mathrm{~kg} / \mathrm{kWh}$ dengan kata lain nilai SFCnya tinggi memiliki efesiensi sistem yang rendah sebesar $27 \%$.

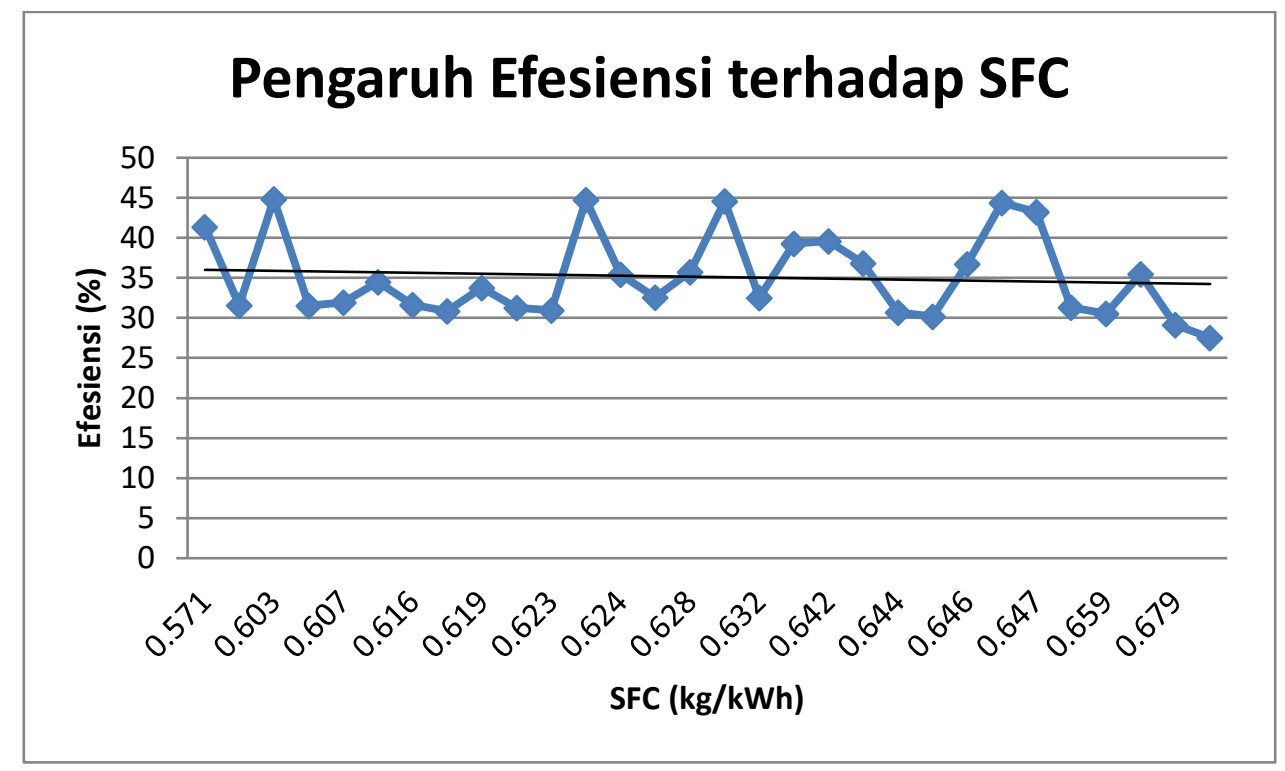

Gambar 6. Hubungan Pengaruh Efesiensi (П) Terhadap SFC Data Per-Hari.

\section{KESIMPULAN}

Berdasarkan analisa data pembahasan, maka pada penelitian ini dapat diperoleh beberapa kesimpulan yaitu:

a. Rata-rata Nilai kalori yang tertinggi memiliki nilai SFC yang rendah dan sebaliknya. Hal ini membuktikan bahwa semakin tinggi nilai kalori yang terdapat pada batubara maka konsumsi bahan bakar spesifiknya (SFC) semakin rendah begitupun sebaliknya.

b. Pada pembebanan 50-60\% dari kapasitas terpasang $1 \times 125 \mathrm{MW}$ memberikan nilai SFC yang relatif tinggi, sedangkan pada pembebanan diatas $80 \%$ dari kapasitas terpasang $1 \times 125 \mathrm{MW}$ memberikan nilai SFC yang relatif rendah, ini artinya pembangkit dapat bekerja optimal jika diopersaikan pada pembebanan diatas $80 \%$.

c. Nilai SFC yang rendah memiliki efesiensi yang tinggi dan nilai SFC yang tinggi memiliki efesiensi yang rendah, kondisi ini memperlihatkan bahwa semakin tinggi nilai SFC pembangkit tersebut maka semakin rendah efesiensi sistemnya begitu pun sebaliknya.

\section{DAFTAR PUSTAKA}

[1] Ramdhani, Wisnu. Analisis Konsumsi Bahan Bakar Pada Pembangkit Listrik Tenaga Gas Uap (PLTGU) Menggunakan Metode Multi Criteria Decision Making (Studi Kasus di PT. Indonesia Power UBP. PLTGU Priok). Diss. Perpustakaan Pascasarjana, 2018.

[2] Winardi, Bambang. "Analisis Konsumsi Bahan Bakar pada Pembangkit Listrik Tenaga Uap (Studi Kasus Di PT. Indonesia Power Semarang)." Seminar Nasional Electrical Invormatics and It's Education, Universitas Diponegoro,(2), 2009.

[3] Sihombing, Fajar, Karnoto Karnoto, and Bambang Winardi. "Analisis Konsumsi Bahan Bakar Pada Pembangkit Listrik Tenaga Uap Studi Kasus PT. PLN Pembangkit Tanjung Jati." Transient 4.4 (2016): 951-957. 
28 Jamal, Chandra Bhuana, Fajri Alihar. Analisis Konsumsi Bahan Bakar Spesifik Pada Pembangkit Listrik Tenaga Uap (PLTU) Jeneponto

[4] Basuki, Cahyo Adi, Agung Nugroho, and Bambang Winardi. Analisis Konsumsi Bahan Bakar Pada Pembangkit Listrik Tenaga Uap Dengan Menggunakan Metode Least Square. Diss. Jurusan Teknik Elektro Fakultas Teknik Undip, 2011.

[5] Bono, Bono; Wahyono, Wahyono. Analisis Konsumsi Batubara Spesifik Ditinjau dari Nilai Kalor Batubara Dan Perubahan Beban Di PLTU Tanjung Jati B Unit 2. Eksergi, 2017, 13.2.

[6] Syahputera, Muhammad Iqbal; Kamal, Dianta Mustofa; Ekayuliana, Arifia. Analisis Pengaruh Nilai Kalori Batubara Terhadap Konsumsi Bahan Bakar dan Biaya Produksi Listrik. In: Seminar Nasional Teknik Mesin 2018.

[7] Nugroho, Agus Adhi. Analisa Pengaruh Kualitas Batubara Terhadap Biaya Pembangkitan (Studi Kasus di PLTU Rembang). Media Elektrika, 2014, 7.1. 